\title{
Effect of PETTLEP program on some sensory motor abilities
}

\section{for swimming players}

\section{Introduction and research problem:}

The ability to visual and kinetic imagery improves as the age progresses among young people, as the ability to imagery reaches its best level at the age of 14 for young people. The assessment and measurement of the level of imagery among the young people is an important study that contributes to determining the level and content of imagery skill for the young in the middle and late childhood.

The kinetic imagery contributes to answering several questions for the youth, through the aim of the imagery process. One of these questions is whether the imagery process is used to identify the general concepts of performance and details related to a specific motor skill to improve it and correct its mistakes or to increase the motivation to win in sports competitions and adjust the control of the player for the purpose of building confidence and strengthening the ability to refocus when tension and anxiety. (3:32)

Magdy Yousef (2016) has indicated that, for several years, imagery has been defined as an effective tool for improving athletic performance and success. As a result, imagery has become one of the most popular psychological strategies used by athletes, coaches, and sports psychologists. Although there is plenty of evidences that focus on the effectiveness of imagery and the mechanisms of its success or the reasons for making imagery more effective, there is no clear answer until now. Traditional conceptual theories are believed to provide vague and insufficient explanations, and thus gets some criticism. However, due to the achievements in cerebral imaging techniques, the latest theory emerging from neuroscience research is the "functional imagery" theory. This theory suggests that when a person perform imagery, it activates similar regions in the brain, which also become active if the individual performs any action (4: 54). 
Imagery in sports can be defined as the use of all senses to recreate or create a sports experience in the mind in order to improve athletic performance during training and competition. To use imagery effectively, Gill, D.L., and Williams, L (2008) suggested some strategies, including practicing imagery regularly and developing it through training with continued physical training as imagery is not a substitute for physical training but rather a skill to improve practice and performance (9)

Weinberg, R. S. (2008) and Gregg, M. J., and Clark, T. (2007) agree that imagery is a technique used in athletic settings to support learning and improve performance. Imagery research in sports usually concentrate on objective changes in the performance of motor skills from pre-test to post-tests in groups of participants who either practiced a physical skill, or practiced a skill using imagery, or taken as a reference group. These researches usually show that persons who exercise physically improve in the post-test more than the Pre-testers, while those in the reference group, do not seem to have any significant improvement. These researches shows that persons involved in the imagery practice also tend to show significant improvements in performance, although not as much as those in physical exercise. (27: 212) (10: 42)

Holmes, P. S., and Collins, D. J. (2001) developed a PETTLEP components equivalence model based on the aforementioned research and theories. The components equivalence model is based on the discovery that the same somatic neuron processes are based on the imagery and the actual movement of the same task, and this "Functional equivalence" provides a possible explanation for the effect of improving imagery performance. The components equivalence aims to assist practitioners in preparing functionally equivalent mental simulation. The components are: physical, environment, task, timing, learning, emotion and perspective (11:34) 


\section{PETTLEP MODEL}
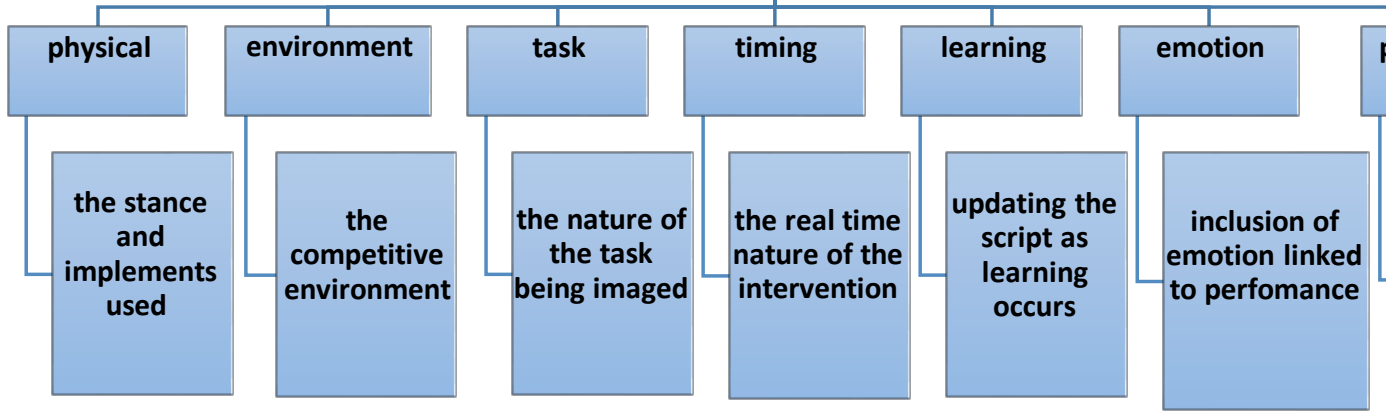

perspective

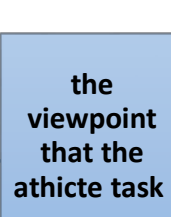

This theory was discovered by Smith, D., Hale, B., and Collins, D. (1998) using the PETTLEP model and several studies have shown that imagery can be effective on sport interventions (22).

Magdy Yousef (2017) explains that, with reference to the theory of kinetic readiness by Jeannerod Guinord (1997), Holmes, P. S., and Collins, D. J. Hale (2001) developed a similar functional model based on Neuroscience and named it the PETTLEP model based on the seven components. The functional neural model confirms that when an individual perceives (makes imagery) a movement, the central nervous system performs the same movement as if the movement is real, due to the fact that the mind stores information in the form of a central display of physical and motor performance. (3:4)

First: The physical component: Magdy Youssef (2017) quoted from Lang, (1999) that the model is related to the physical responses of the player in the athletic situation.

Second: The environment component: It refers to the environment in which the imagery is made and should take place in an environment similar to the one in which the competition is located and an environment identical to the real. 
Third: The timing component, which indicates that the imagery is done at the correct speed (that is, the speed at which work must be completed). Real time speed helps in perfect timing for kinetic performance.

Fourth: The task component: Syer, J., and Connolly, C. (1984) and Magill (2004) shows that the imagery task must be closely matched to the real task and the content of the imagery should be mission-specific, with the performer focusing on the same thoughts, feelings, and actions as his focus during competitive performance.

Fifth: the learning component: expresses the modification of the content of the imagery in relation to the learning stage, the kinetic imagery and the associated responses will change over time when learning occurs.

Sixth: The emotion component: Magdy Youssef (2017) refers to the missing link in sports performance, where the athlete should try to experience all the emotions and excitations related to performance to achieve an ideal functional equivalence.

Seventh: The Perspective component: The Perspective is the last component of the PETTLEP components equivalence model which indicates whether the athlete conceives (imagery) through an internal perspective (first person), or an external perspective (third person) $\quad(3: 22)(24: 179)(14: 157)$

Magdy Youssef (2016) quoted from (Vealey, R.S. and Greenlea, C.A(2001) the definition of imagery as "using all the senses to create or recreate an experience in the mind" $(4: 67)$

Holmes, P. S., and Collins, D. J. (2001) and Lang, P. J. et al. (1980) noted that the approach does not takes into account the physical effects of relaxation, which appear in complete contrast to the physical condition of the performing athlete and that imagery is most effective when it includes all the senses that should be used 
and the motor sensations that should be experienced during actual performance (11:65) (13:114)

The Vienna system is considered one of the most important recent psychological laboratory systems and is also considered one of the leading international procedures in the field of examination, measurement and psychological diagnosis supported by computers, that apply various types of tests by employing and developing the latest technology as the computer provides us with a higher possible level of accuracy and objectivity also provides us with an evaluation of test results free of errors and can measure values that cannot be measured by the traditional paper and pen method, as the Vienna Tests System has been prepared for examination, measurement and psychological diagnosis in a way that makes the complex psychological tests simple and convenient by employing and developing the latest technology within this system (2)

The Vienna test system (vts) is able to analyze many psychological abilities in the sports field; The system (vts) was developed by schyhfried gmph (modeling, Austria) as a valid and reliable tool for psychological assessment and contains countless number of tests that are related to sports psychology and is suitable for evaluating both the ability and personality of athletes, and includes tests to measure the accuracy of observation, reaction speed, Visual tracking of a moving target, reaction time, and the ability to estimate (anticipate) the time, speed, distance traveled by a moving target, attention, focus, continuity of performance in dispersion, remember oral instructions, and short-term memory (20: 98) (21: 43)

The Vienna system (VTS) is widely used to conduct psychological tests for athletes in various sports activities $(18: 35)$.

The psychomotor abilities is defined as the individual's physical, skill, motor, and cognitive capabilities that he possesses in a preliminary level, which determines the level of the individual and his ability to learn and acquire athletic and motor 
skills" and includes various skills such as Synergy between hand and eye, balance, and reaction time. The psychomotor abilities arise from the integration between cognitive and physical functions (7: 58) (19:35)

- The researchers think that most of those in charge of the training process devote more time for the physical, skilled, and planning side and neglect the applied psychological side despite its importance in the sports field, which made the matter important and a subject of research and study.

Moreover, avoiding the use of measuring devices in some researches led to some ambiguity in the results, the researchers found it necessary to apply the program on a group of swimmers to study the effect of the bio equivalent program for mental imagery using the components of (PETTLEP) on improving some psychomotor capabilities using the Vienna system

\section{Objective of the study:}

Identify the effect of a mental imagery program using the bio equivalent dimensions on improving some psychomotor capabilities in terms of the Vienna test system on swimming players by:

1- Finding the effect of a mental imagery program on the dimensions of the bio equivalent.

2- Finding the effect of a mental imagery program on improving some psychomotor abilities in terms of the Vienna test system

\section{Hypotheses of the study:}

1- There are statistically significant differences between the pre and post measurements of the experimental group for bio equivalent parameters in favor of the post measurements. 
2- There are statistically significant differences between the pre and post measurements of the experimental group in the psychomotor abilities in terms of the Vienna system (VTS) in favor of the post measurements.

\section{Research procedures:}

The researchers used the descriptive experimental approach due to its relevance to the nature of the research by using the experimental design of one group using the pre and post measurement method.

\section{- Research fields.}

The human Scope.

The research sample was chosen randomly from the Alexandria Governorate swimmers registered in clubs and students of the faculty of physical education. A research sample of (25) players was selected of age below 18 years.

\section{Place Scope.}

- Faculty of Physical Education - Boys Abu Kir.

- Psychological laboratory for the use of the Vienna measuring device.

\section{Time Scope.}

The program was implemented in the 2019-2020 season, during the period 28 / 9/2019 - to $12 / 12 / 2019$

\section{Data collection tools.}

The means and tools appropriate to the nature and objectives of the study were identified:

\section{1- Bio imagery scale}

The scale was prepared in Arabic by Magdy Yousef (2017) aiming to identify the degree to which the player can use his senses during the bio imagery and depends on two methods of mental training on motor skills used by athletes. The first 
method aims to imagery or create a picture of movement in your mind, while the second method aims to try to feel the movement without actually doing the movement, and it depends on an external perspective, an internal perspective, and a sensory motor perspective, through (7) axes that represent different imagery positions, namely: -

The visual imagery axis (internal, external and sensory motor)

\begin{tabular}{|c|c|c|c|c|c|c|}
\hline 1 & 2 & 3 & 4 & 5 & 6 & 7 \\
\hline $\begin{array}{l}\text { Very } \\
\text { difficult to } \\
\text { imagery }\end{array}$ & $\begin{array}{l}\text { Difficult to } \\
\text { imagery }\end{array}$ & $\begin{array}{l}\text { Difficult to } \\
\text { imagery }\end{array}$ & $\begin{array}{l}\text { Difficult to } \\
\text { imagery } \\
\text { to some } \\
\text { extent }\end{array}$ & $\begin{array}{l}\text { Very easy } \\
\text { to imagery }\end{array}$ & $\begin{array}{l}\text { Easy to } \\
\text { imagery }\end{array}$ & $\begin{array}{ll}\text { Easy } & \text { to } \\
\text { imagery } & \text { to } \\
\text { some } & \\
\text { extent } & \end{array}$ \\
\hline
\end{tabular}

\section{Vienna test system}

The Vienna system contains a total of 14 tests, 4 of which were selected, the most closely related to the research topic. Using the Vienna system, psychomotor capabilities were measured. The work on the system is done according to a specific procedure, which are:

1- Entering the complete examined data in terms of (date - age - type - school stage)

2- Choosing the type of test or examination

3- Choosing the specific time for the test

4- Explanation of the test for the subject before application

5- Implementation of the test

6- Test assessment

7- Review or print test results

\section{Statistical Analysis:}

Statistical processors were found using SPSS version 20 as follows: 
-. Mean

- Stander Deviation

- Median

- Std. Error of Mean

-. Skewness

- Kurtosis

- Paired Samples T test

- The percentage of improvement

\section{Review of Results and discussion}

First: Results of the first hypothesis

Table (1) Statistical significance of the bio equivalence scale (external imagery axis) and the percentage of improvement of the experimental group before and after the experiment $(n=25)$

\begin{tabular}{|c|c|c|c|c|c|c|c|c|c|c|}
\hline \multirow{2}{*}{$\begin{array}{c}\text { Statistical } \\
\text { Indications }\end{array}$} & \multirow[t]{2}{*}{$\begin{array}{c}\text { measuring } \\
\text { unit }\end{array}$} & \multicolumn{2}{|c|}{$\begin{array}{c}\text { Tribal } \\
\text { measurement }\end{array}$} & \multicolumn{2}{|c|}{$\begin{array}{c}\text { Dimensional } \\
\text { measurement }\end{array}$} & \multicolumn{2}{|c|}{$\begin{array}{c}\text { The } \\
\text { difference } \\
\text { between the } \\
\text { two mediums }\end{array}$} & \multirow[t]{2}{*}{$\begin{array}{c}\text { Value } \\
\text { of }(t)\end{array}$} & \multirow[t]{2}{*}{$\begin{array}{c}\text { Significance } \\
\text { level }\end{array}$} & \multirow[t]{2}{*}{$\begin{array}{c}\text { Improvement } \\
\%\end{array}$} \\
\hline & & M & SD \pm & $\mathbf{M}$ & SD \pm & $\mathbf{M}$ & SD \pm & & & \\
\hline Knee lift & Degree & 4.56 & 1.45 & 6.16 & 0.75 & 1.60 & 1.58 & *5.06 & 0.00 & $\% 35.09$ \\
\hline Jumping & Degree & 2.48 & 1.00 & 5.44 & 1.12 & 2.96 & 1.24 & *11.93 & 0.00 & $\% 119.35$ \\
\hline $\begin{array}{c}\text { The movement } \\
\text { of farmers }\end{array}$ & Degree & 5.04 & 0.93 & 6.32 & 0.85 & 1.28 & 1.57 & *4.08 & 0.00 & $\% 25.40$ \\
\hline Drape the waist & Degree & 5.16 & 1.14 & 6.48 & 0.71 & 1.32 & 1.18 & ${ }^{\star} 5.59$ & 0.00 & $\% 25.58$ \\
\hline
\end{tabular}

\section{Morale at the level of $0.05={ }^{*}(2.06)$}

From table (1) of the statistical significance of the research sample before and after the experiment, there are statistically significant differences at the level (0.05) in favor of the post measurement in the axis of external imagery, where the calculated value of $(\mathrm{T})$ 
ranged from (4.08 - 11.93) which is greater than the table value of $(\mathrm{T})$ at 0.05 level (2.06). The percentage of improvement range is $(25.40 \%-119.35 \%)$ in favor of post measurements.

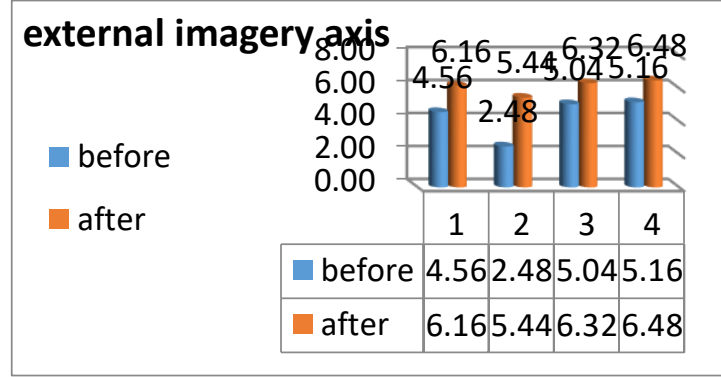

\section{Table ( 2)}

Statistical significance in measuring the bio equivalence (axis of internal imagery) and the percentage of improvement for the experimental group before and after the experiment $(n=25)$

\begin{tabular}{|c|c|c|c|c|c|c|c|c|c|c|}
\hline \multirow[t]{2}{*}{$\begin{array}{l}\text { Statistical } \\
\text { Indications }\end{array}$} & \multirow[t]{2}{*}{$\begin{array}{c}\text { measuring } \\
\text { unit }\end{array}$} & \multicolumn{2}{|c|}{\begin{tabular}{|c} 
Tribal \\
measurement
\end{tabular}} & \multicolumn{2}{|c|}{$\begin{array}{l}\text { Dimensional } \\
\text { measurement }\end{array}$} & \multicolumn{2}{|c|}{$\begin{array}{c}\text { The } \\
\text { difference } \\
\text { between the } \\
\text { two mediums }\end{array}$} & \multirow[t]{2}{*}{$\begin{array}{c}\text { Value } \\
\text { of }(t)\end{array}$} & \multirow[t]{2}{*}{$\begin{array}{c}\text { Significance } \\
\text { level }\end{array}$} & \multirow[t]{2}{*}{$\begin{array}{c}\text { Improvement } \\
\%\end{array}$} \\
\hline & & M & SD \pm & M & SD \pm & M & SD \pm & & & \\
\hline Knee lift & Degree & 4.28 & 1.24 & 6.08 & 0.95 & 1.80 & 1.68 & ${ }^{*} 5.35$ & 0.00 & $\% 42.06$ \\
\hline Jumping & Degree & 2.60 & 1.22 & 6.16 & 0.85 & 3.56 & 1.36 & *13.12 & 0.00 & $\% 136.92$ \\
\hline $\begin{array}{c}\text { The movement } \\
\text { of farmers }\end{array}$ & Degree & 4.40 & 1.29 & 6.48 & 0.71 & 2.08 & 1.47 & ${ }^{*} 7.08$ & 0.00 & $\% 47.27$ \\
\hline Drape the waist & Degree & 4.12 & 1.54 & 6.36 & 0.76 & 2.24 & 1.76 & ${ }^{*} 6.35$ & 0.00 & $\% 54.37$ \\
\hline
\end{tabular}

\section{Morale at the level of $0.05=(2.06)$}

From table (2) of the statistical significance of the research sample in before and after the experiment, there are statistically significant differences at level (0.05) in favor of post measurement in the axis of internal imagery, where the calculated value of $(\mathrm{T})$ ranged from (5.35-13.12) which is greater than the table value of (T) are at the level of 0.05 (2.06). The percentage of improvement is $(42.06 \%-136.92 \%)$ in favor of post measurements. 


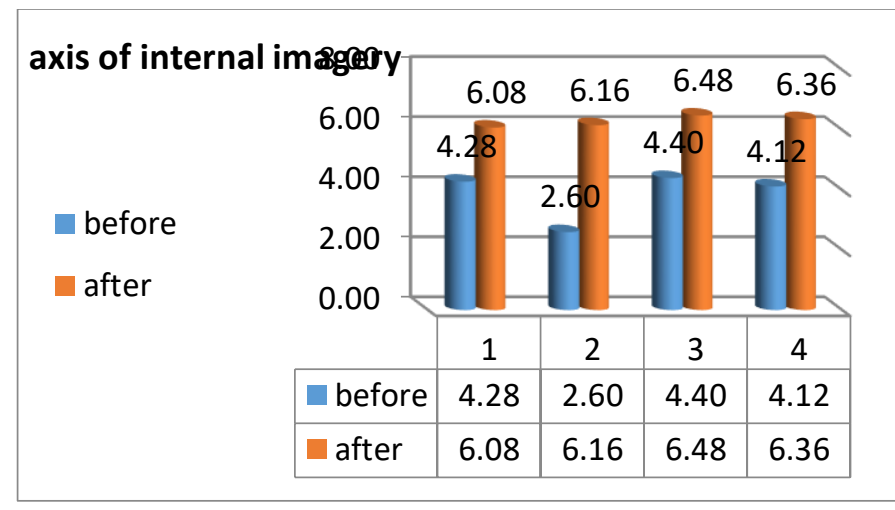

Table (3)

Statistical significance in measuring the bio equivalence (sensory motor axis) and the percentage of improvement of the experimental group before and after the experiment $(n=25)$

\begin{tabular}{|c|c|c|c|c|c|c|c|c|c|c|}
\hline \multirow[t]{2}{*}{$\begin{array}{c}\text { Statistical } \\
\text { Indications }\end{array}$} & \multirow[t]{2}{*}{$\begin{array}{c}\text { measuring } \\
\text { unit }\end{array}$} & \multicolumn{2}{|c|}{$\begin{array}{c}\text { Tribal } \\
\text { measurement }\end{array}$} & \multicolumn{2}{|c|}{$\begin{array}{c}\text { Dimensional } \\
\text { measurement }\end{array}$} & \multicolumn{2}{|c|}{$\begin{array}{c}\text { The } \\
\text { difference } \\
\text { between the } \\
\text { two mediums }\end{array}$} & \multirow[t]{2}{*}{$\begin{array}{l}\text { Value } \\
\text { of }(t)\end{array}$} & \multirow[t]{2}{*}{$\begin{array}{c}\text { Significance } \\
\text { level }\end{array}$} & \multirow[t]{2}{*}{$\begin{array}{c}\text { Improvement } \\
\%\end{array}$} \\
\hline & & M & SD \pm & $\mathbf{M}$ & SD \pm & M & SD \pm & & & \\
\hline Knee lift & Degree & 4.12 & 1.17 & 6.48 & 0.71 & 2.36 & 1.38 & *8.55 & 0.00 & $\% 57.28$ \\
\hline Jumping & Degree & 2.28 & 1.10 & 6.04 & 0.93 & 3.76 & 1.33 & *14.12 & 0.00 & \%164.91 \\
\hline $\begin{array}{c}\text { The movement } \\
\text { of farmers }\end{array}$ & Degree & 4.16 & 1.14 & 6.16 & 0.85 & 2.00 & 1.58 & ${ }^{*} 6.32$ & 0.00 & $\% 48.08$ \\
\hline Drape the waist & Degree & 4.64 & 1.22 & 6.64 & 0.49 & 2.00 & 1.32 & ${ }^{*} 7.56$ & 0.00 & $\% 43.10$ \\
\hline
\end{tabular}

Morale at the level of $0.05=(2.06)$

From table (3) of the statistical significance of the research sample before and after the experiment, there are statistically significant differences at level (0.05) in favor of the post measurement in axis of sensory motor imagery, where the calculated value of $(T)$ ranged from (6.32-14.12) which is greater than the table value of $(\mathrm{T})$ at the level of 0.05 (2.06), and the improvement percentage reached $(43.10 \%-164.91 \%)$ in favor of post measurements. 


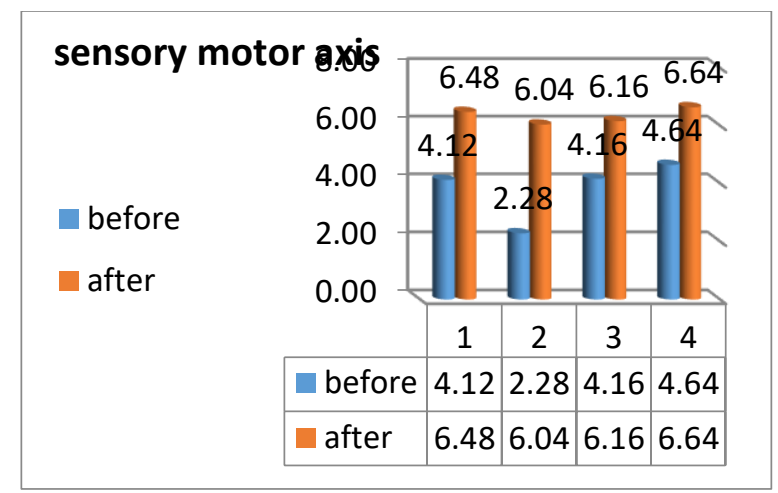

\section{Second: Discussion of the first hypothesis: -}

There are statistically significant differences between the pre and post measurements of the experimental group in the bio equivelance axes in favor of the post measurement.

It is clear from tables $(1,2,3)$ of the statistical significance of the research sample before and after the experiment, that there are statistically significant differences at the level of (0.05) in favor of dimensional measurement in the axes of bio imagery (external - internal - sensory motor) where the calculated value of (T) ranged from (4.08 - 14.12) is greater than the table value of (T) at level 0.05 (2.06) and the improvement percentage ranged (25.40\% -164.61\%) in favor of the post measurement.

The researchers attribute the improvement to the implementation of the proposed program which includes the vital elements and appropriate of the competition environment to which the experimental group was subjected. There has been a development in the axes of bio imagery (external and internal and sensory motor), i.e. the sense of movement and performance skill is affected to a large percentage by the proposed mental training program in the axes of bio imagery PETTLEP, where the results proved that the axis of internal and external and sensory motor are the axes affected by the program because of its significance to lead the player during the performance. 
The results of this study agrees with that of Cumming et al. (2012) in that mixing external visual imagery with sensory motor processing will lead to high performance, and by processing the external visual image for the second time, more information will be available on the nature of the shape. In our study, the researchers are interested in the importance of the integration of knowledge through the task, education, and perspection. (8: 213)

This study also agrees with the study of Magdy Yousef (2016), Mohamed Ibrahim Rakha (2018), and Briar John (2018) where the study results indicated that the improvement in the experimental group was a result of the proposed program.There was also an improvement in the post measurements of hockey players and ACAD club volleyball players in Iraq. The results showed a significant improvement in the axis of external imagery that was attributed to implemented program. (4) (5) (1)

The results of this study is also consistent with the that of Riccardo, V., and Etzkowitz, H. (2010) in that when the kinetic/internal visual imagery is considered, the conclusions drawn will support the research in the kinetic / internal visual imagery. Considering the traditional definitions of kinetic imagery, it must be remembered that imagery is a cognitive product. Hence, kinetic imagery work is to process response information that may mimic the motor elements accompanying kinetic performance during visual imagery. The conscious and subconscious kinetic imagery cannot exist simultaneously with each other at the same time as it is possible that some of the kinetic elements used during the performance are not available for the conscious imagery. But it can be accessed through modifications involved in adequate responses such as (the self-video model). In the case of subconscious kinetic imagery, it is carried out by a neurotransmitter accompanying the performance. This situation is completely different with the conscious kinetic 
imagery based internally. However, all methods lead to the same act in equal situations.

Interacting with the education component of the functional equivalence program for bio imagery presents a core issue for sports psychologists.

This atudy is consistent with study of Smith, D. et al. (2007) in that imagery using PETTLEP aims to produce a more realistic and functional imagery experience than traditional imagery methods through factors such as wearing the right clothes or visualize in the right environment. (23: 85)

Magdy Hassan Youssef (2017) confirms that if the athlete visualizes himself kicking the ball, the brain regions will activate during the imagery of the task, and it is believed that this activation through imagery can strengthen the nervous activity that occurs during the implementation of the movement and thus improving the motor output and athlete success. This stimulation of the nervous areas during imagery can also lead to other physiological responses that are reflective of the actual situation such as increases in heart rate, frequency of ventilation and muscle activity. Some components are a mixture of traditional features used in imagery studies for several years (example: task and perspective) and some are relatively new that sometimes face the traditional methods (example: physical, timing). Because the PETTLEP functional equivalence model for kinetic imagery has been combined with numerous studies and supportive results which indicates that the most integrated elements and the most successful imagery tends to be based on sports imagery, and as a result, the functional equivalence model of motor imagery has become a well-prepared and a general tool used to increase the effectiveness of imagery. (3: 30,31$)$ 
Table (4) the statistical significance of Vienna attention and focus scale

(Cognition) (COG) and the percentage of improvement of the experimental group before and after the experiment $(n=25)$

\begin{tabular}{|c|c|c|c|c|c|c|c|c|c|c|}
\hline \multirow{2}{*}{$\begin{array}{l}\text { Statistical } \\
\text { Indications }\end{array}$} & \multirow[t]{2}{*}{$\begin{array}{c}\text { measuring } \\
\text { unit }\end{array}$} & \multicolumn{2}{|c|}{$\begin{array}{c}\text { Tribal } \\
\text { measurement }\end{array}$} & \multicolumn{2}{|c|}{$\begin{array}{l}\text { Dimensional } \\
\text { measurement }\end{array}$} & \multicolumn{2}{|c|}{$\begin{array}{c}\text { The } \\
\text { difference } \\
\text { between the } \\
\text { two mediums }\end{array}$} & \multirow[t]{2}{*}{$\begin{array}{l}\text { Value } \\
\text { of }(t)\end{array}$} & \multirow[t]{2}{*}{$\begin{array}{c}\text { Significance } \\
\text { level }\end{array}$} & \multirow[t]{2}{*}{$\begin{array}{c}\text { Improvement } \\
\%\end{array}$} \\
\hline & & $\mathbf{M}$ & SD \pm & M & SD \pm & $\mathbf{M}$ & SD \pm & & & \\
\hline $\begin{array}{l}\text { Sum "correct } \\
\text { reactions" }\end{array}$ & Degree & 61.88 & 7.60 & 70.56 & 8.34 & 8.68 & 5.60 & *7.76 & 0.00 & $\% 14.03$ \\
\hline $\begin{array}{l}\text { Sum "incorrect } \\
\text { reactions" }\end{array}$ & Degree & 24.72 & 7.45 & 17.68 & 6.77 & 7.04 & 4.93 & *7.14 & 0.00 & $\% 28.48$ \\
\hline $\begin{array}{l}\text { Sum "incorrect non- } \\
\text { reactions" }\end{array}$ & Degree & 17.20 & 7.92 & 13.88 & 5.32 & 3.32 & 7.44 & ${ }^{*} 2.23$ & 0.04 & $\% 19.30$ \\
\hline $\begin{array}{l}\text { Mean time "correct } \\
\text { reactions" }\end{array}$ & sec & 1.10 & 0.13 & 1.03 & 0.10 & 0.06 & 0.15 & $* 2.10$ & 0.05 & $\% 5.83$ \\
\hline $\begin{array}{l}\text { Mean time "incorrect } \\
\text { reactions" }\end{array}$ & sec & 1.14 & 0.09 & 1.14 & 0.18 & 0.00 & 0.17 & 0.11 & 0.91 & $\% 0.33$ \\
\hline
\end{tabular}

\section{Morale at the level of $0.05=(2.06)$}

It is clear from Table (4) of the statistical significance of the research sample before and after the experiment, that there are statistically significant differences at level $(0.05)$ in favor of the post measurement in the dimension (number of correct reactions; number of incorrect reactions; no of no reactions; mean time for correct reactions) where the value of Calculated $(\mathrm{T})$ was $(2.10-7.76)$ which is greater than the tabulated value of (T) at the level of 0.05 (2.06). No statistically significant differences at the level (0.05) in the dimension (Mean time "incorrect reactions") where the calculated value of $(\mathrm{T})$ was $(0.11)$ which is less than the tabulated value of $(\mathrm{T})$ at the level of 0.05 (2.06). The percentage of improvement ranged $(0.33 \%-28.48 \%)$ in favor of post measurements. 
Table (5) The statistical significance of the Vienna attention and focus scale of

Sustained Attention (DAUF) and the percentage of improvement for the experimental group before and after the experiment $(n=25)$

\begin{tabular}{|c|c|c|c|c|c|c|c|c|c|c|}
\hline \multirow[t]{2}{*}{$\begin{array}{l}\text { Statistical } \\
\text { Indications }\end{array}$} & \multirow[t]{2}{*}{$\begin{array}{c}\text { measuring } \\
\text { unit }\end{array}$} & \multicolumn{2}{|c|}{$\begin{array}{c}\text { Tribal } \\
\text { measurement }\end{array}$} & \multicolumn{2}{|c|}{$\begin{array}{l}\text { Dimensional } \\
\text { measurement }\end{array}$} & \multicolumn{2}{|c|}{$\begin{array}{c}\text { The } \\
\text { difference } \\
\text { between the } \\
\text { two } \\
\text { mediums }\end{array}$} & \multirow[t]{2}{*}{$\begin{array}{l}\text { Value } \\
\text { of }(t)\end{array}$} & \multirow[t]{2}{*}{$\begin{array}{c}\text { Significance } \\
\text { level }\end{array}$} & \multirow[t]{2}{*}{$\begin{array}{c}\text { Improvement } \\
\%\end{array}$} \\
\hline & & $\mathbf{M}$ & SD \pm & M & SD \pm & M & SD \pm & & & \\
\hline Sum correct & Degree & 108.92 & 5.09 & 116.32 & 3.18 & 7.40 & 4.97 & *7.44 & 0.00 & $\% 6.79$ \\
\hline $\begin{array}{l}\text { Mean time correct } \\
\text { (sec.) }\end{array}$ & sec & 1.07 & 0.22 & 0.85 & 0.11 & 0.22 & 0.23 & *4.78 & 0.00 & $\% 20.21$ \\
\hline Sum incorrect & Degree & 7.08 & 2.63 & 4.64 & 2.74 & 2.44 & 2.29 & *5.32 & 0.00 & $\% 34.46$ \\
\hline $\begin{array}{c}\text { Mean time } \\
\text { incorrect (sec.) }\end{array}$ & sec & 1.33 & 0.49 & 1.02 & 0.45 & 0.31 & 0.45 & ${ }^{*} 3.49$ & 0.00 & $\% 23.43$ \\
\hline
\end{tabular}

\section{Morale at the level of $0.05=(2.06)$}

It is clear from table (5) of the statistical significance of the research sample before and after the experiment, that there are statistically significant differences at the level of (0.05) in favor of post measurement in the dimension (the number of correct reactions; the time of correct reactions; number of incorrect reactions; the time of incorrect reactions) where the value of calculated $(\mathrm{T})$ ranged $(3.49-7.44)$ which is greater than the value of the tabulated $(\mathrm{T})$ at the level of 0.05 (2.06). The percentage of improvement ranged $(6.79 \%-34.46 \%)$ in favor of post measurements. 
Table ( 6) Statistical Significance for the Vienna Attention Speed and Focus

Scale Determination Test (DT) and the percentage of improvement for the experimental group before and after the experiment $(n=25)$

\begin{tabular}{|c|c|c|c|c|c|c|c|c|c|c|}
\hline \multirow[t]{2}{*}{$\begin{array}{l}\text { Statistical } \\
\text { Indication }\end{array}$} & \multirow[t]{2}{*}{$\begin{array}{c}\text { measuring } \\
\text { unit }\end{array}$} & \multicolumn{2}{|c|}{$\begin{array}{c}\text { Tribal } \\
\text { measurement }\end{array}$} & \multicolumn{2}{|c|}{$\begin{array}{l}\text { Dimensional } \\
\text { measurement }\end{array}$} & \multicolumn{2}{|c|}{$\begin{array}{c}\text { The } \\
\text { difference } \\
\text { between the } \\
\text { two } \\
\text { mediums }\end{array}$} & \multirow[t]{2}{*}{$\begin{array}{l}\text { Value } \\
\text { of }(t)\end{array}$} & \multirow[t]{2}{*}{$\begin{array}{c}\text { Significance } \\
\text { level }\end{array}$} & \multirow[t]{2}{*}{$\begin{array}{c}\text { Improvement } \\
\%\end{array}$} \\
\hline & & $\mathbf{M}$ & SD \pm & $\mathbf{M}$ & SD \pm & $\mathbf{M}$ & SD \pm & & & \\
\hline Correct & Degree & 206.08 & 29.81 & 229.44 & 34.83 & 23.36 & 28.66 & *4.07 & 0.00 & $\% 11.34$ \\
\hline Incorrect & Degree & 27.80 & 14.81 & 23.40 & 12.09 & 4.40 & 16.84 & 1.31 & 0.20 & $\% 15.83$ \\
\hline omitted & Degree & 26.20 & 9.00 & 20.40 & 9.64 & 5.80 & 10.45 & ${ }^{*} 2.78$ & 0.01 & $\% 22.14$ \\
\hline $\begin{array}{c}\text { Median reaction } \\
\text { time }\end{array}$ & msec & 0.77 & 0.07 & 0.72 & 0.07 & 0.06 & 0.04 & $* 7.76$ & 0.00 & $\% 7.19$ \\
\hline Reactions & Degree & 233.88 & 38.10 & 255.52 & 37.35 & 21.64 & 30.95 & $* 3.50$ & 0.00 & $\% 9.25$ \\
\hline
\end{tabular}

Morale at the level of $0.05=\mathbf{( 2 . 0 6 )}$

It is clear from the table (6) of the statistical significance of the research sample in the before and after the experiment, that there are statistically significant differences at the level (0.05) in favor of post measurements in the dimension (number of correct reactions; number of no reactions; Median reaction time), where the calculated value of (T) ranged (2.78-7.76) which is greater than the tabulated value of $(\mathrm{T})$ at the level of 0.05 (2.06). No statistically significant differences was noticed at the level of (0.05) in the dimension (the number of incorrect reactions) where the calculated value of (T) was (1.31) which is less than the tabulated value of $(\mathrm{T})$ at the level of $0.05(2.06)$. The percentage of improvement ranged $(7.19 \%-22.14 \%)$ in favor of post measurements. 


\section{Table(7)}

Statistical significance of the Vienna Reaction Time Scale and the percentage of improvement of the experimental group before and after the experiment $(n=25)$

\begin{tabular}{|c|c|c|c|c|c|c|c|c|c|c|}
\hline \multirow[t]{2}{*}{$\begin{array}{c}\text { Statistical } \\
\text { Indication. }\end{array}$} & \multirow[t]{2}{*}{$\begin{array}{c}\text { measuring } \\
\text { unit }\end{array}$} & \multicolumn{2}{|c|}{$\begin{array}{c}\text { Tribal } \\
\text { measurement }\end{array}$} & \multicolumn{2}{|c|}{$\begin{array}{l}\text { Dimensional } \\
\text { measurement }\end{array}$} & \multicolumn{2}{|c|}{\begin{tabular}{|c} 
The \\
difference \\
between the \\
two \\
mediums
\end{tabular}} & \multirow[t]{2}{*}{$\begin{array}{l}\text { Value } \\
\text { of }(t)\end{array}$} & \multirow[t]{2}{*}{$\begin{array}{c}\text { Significance } \\
\text { level }\end{array}$} & \multirow[t]{2}{*}{$\begin{array}{c}\text { Improvement } \\
\%\end{array}$} \\
\hline & & M & SD \pm & M & SD \pm & M & SD \pm & & & \\
\hline Mean reaction time & msec & 291.56 & 35.49 & 270.92 & 48.39 & 20.64 & 51.10 & ${ }^{*} 2.09$ & 0.04 & $\% 7.08$ \\
\hline Mean motor time & msec & 135.96 & 37.51 & 119.72 & 32.38 & 16.24 & 36.17 & ${ }^{*} 2.24$ & 0.03 & $\% 11.94$ \\
\hline $\begin{array}{l}\text { Measure of dispersion } \\
\text { reaction time }\end{array}$ & msec & 39.68 & 15.15 & 35.28 & 10.12 & 4.40 & 14.62 & 1.50 & 0.15 & $\% 11.09$ \\
\hline $\begin{array}{l}\text { Measure of dispersion } \\
\text { motor time }\end{array}$ & msec & 27.20 & 14.25 & 21.64 & 7.70 & 5.56 & 14.80 & 1.88 & 0.07 & $\% 20.44$ \\
\hline Correct reaction & Degree & 27.76 & 0.60 & 27.64 & 0.76 & 0.12 & 0.97 & 0.62 & 0.54 & $\% 0.43$ \\
\hline No reaction & Degree & 0.13 & 0.34 & 0.29 & 0.69 & 0.17 & 0.76 & 1.07 & 0.29 & $\% 133.33$ \\
\hline Incomplete reaction & Degree & 0.12 & 0.44 & 0.08 & 0.40 & 0.04 & 0.45 & 0.44 & 0.66 & $\% 33.33$ \\
\hline
\end{tabular}

\section{Morale at the level of $0.05=(2.06)$}

It is clear from Table (7) of the statistical significance of the research sample in the before and after the experiment, that there are statistically significant differences at the level of (0.05) in favor of the post measurements in the dimension (Mean motor response time; Mean reaction time) where the calculated value of (T) ranged (2.09 2.24) which is greater than the tabulated value of (T) at the level of 0.05 (2.06). The absence of statistically significant differences at the level of (0.05) in the dimension of (Measure of dispersion during reaction time; Correct reactions; No reactions, Incomplete reaction) where the calculated value of $(\mathrm{T})$ ranged $(0.44 ; 1.88)$ which is less than the tabulated value of $(\mathrm{T})$ at the level of 0.05 (2.06). The percentage of improvement ranged $(0.43 \%-133.33 \%)$ in favor of post measurements. 

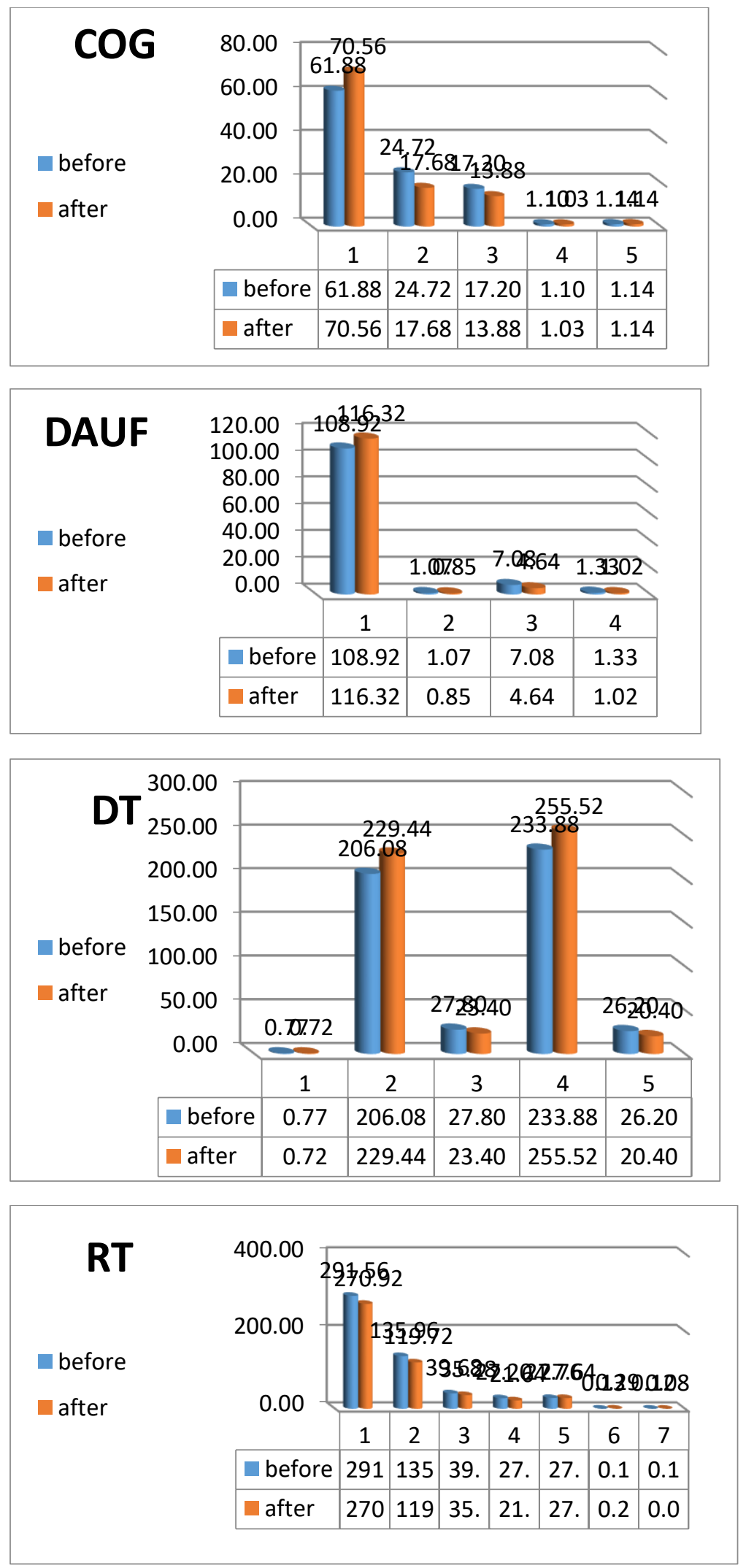


\section{Second: - Discussion of the second hypothesis: -}

There are statistically significant differences between the pre and post measurements of the experimental group in the psychomotor capabilities in terms of the Vienna system (VTS) in favor of post measurements.

It is clear from the tables $(4,5,6,7)$ of the statistical significance of the research sample in the before and after the experiment, that there are statistically significant differences at the level (0.05) in favor of post measurements in the dimension (in the psychomotor capabilities) where the calculated value of $(\mathrm{T})$ ranged from (2.97.76) which is greater than Tabulated value of (T) at 0.05 (2.06). However, there were no statistically significant differences at (0.05) in (mean of wrong reactions number of wrong reactions - measurement of dispersion during the reaction; measurement of dispersion during the time of motor reaction; correct reaction; no reactions, incomplete reactions) where the calculated value of $(\mathrm{T})$ ranged $(0.11$; 1.88)) which is less than the tabulated value of $(T)$ at the level of 0.05 (2.06). The percentage of improvement $(0.33 \%-28.48 \%)$ in favor of post measurements.

Through the previous results, the researchers attribute the improvement in the psychomotor abilities using the Vienna system to the progress or improvement in the nature and contents of the training program that includes the vital elements and appropriate to the competition environment to which the experimental group was subjected. This gives an indication of the effect of the program and the improvement of the psychomotor capabilities. An indication is also given of the effectiveness of the bio equivalence elements in improving the variables of the Vienna system, especially those that depend on the times. The researchers attribute this progress to the nature and contents of the training program that the sample was subject to, as the results shows a significant improvement in increasing the ability of swimmers in the psychomotor abilities within competition and training. 
The results of the current study are in consistent with the results of Mortada Kazim Abadi (2019) and Mastrangelo (2003) that there is a relationship between improving the skill of attention and focus and the proposed program and also the ability of the Vienna system to give a result that reflects the true level of the player. Mastrangelo (2003) reported that the goal of conducting training and qualification with the help of a computer is to improve the cognitive and knowledge capabilities of the examined subjects using the latest technology. And that the development and progress in this field made the application of training in cognitive rehabilitation with a computer is possible using the Vienna system (6) (16)

The results of the current study are in consistent with the results of Turosz MA et al. (2007), Johne M. et al. (2013), and Mańkowska M. et al. (2015). These studies indicates different correlations in the psychomotor abilities of athletes in responding to Vienna test system (vst) due to the level of sports and the duration of training (25) (12) )(15)

Nathanael Ong (2015) indicates that the Vienna Test System is a tool for identifying the differences that exist between different sports activities and helping sports psychologists to understand the various requirements from athletes in each sports activity and this is shown in the correlation between the reaction speed test, the focus of attention, the distinction between sounds, colors, and pedals of the foot, the visual tracking test among dispersants, and the ability to observe and visual tracking of a specific target among side dispersions; measuring the strength of the forward focus in the presence of side dispersions (17) 


\section{Fifth: Conclusion and Recommendation}

\section{Conclusion:}

In the light of the results reached and related to the objectives of the research and in the light of the method used and within the limits of the nature and characteristics of the study sample, the measuring tools used, and the statistical analysis, the following conclusions have been reached: -

1- The mental training program using the PETTLEP bio equivalence (imagery) elements has a positive effect on improving the psychomotor capabilities of the research sample.

2- $\mathrm{T}$ The mental training program using the PETTLEP bio equivalence (imagery) elements has a positive effect on visual imagery (internal, external and sensory motor) axes within the bio imagery scale of the research sample.

3- The mental training program using the PETTLEP bio equivalence (imagery) elements using Vienna variables (vst) has a positive effect on mental variables (focus of attention, focus of attention and continuity of performance among distractors, reaction speed, reaction time, mental imagery, cognitive function, and motivational of mental imagery)

4- The use of modern technologies, such as the Vienna test system, helps in obtaining accurate and real results of the study variables, which were difficult to measure with the same accuracy and reliability using traditional methods.

\section{Recommendation:}

- Adopting scientific foundations in designing training programs using the proposed PETTLEP vital elements, which includes mental and psychological training when developing training programs for players at all stages.

- The necessity of conducting periodic tests on the players at regular intervals according to the training program and the Vienna test system to measure, 
examine, and diagnose the players during the training season to find out the actual level of players in the skill and then reach the highest levels.

- Using psychological programs and the Vienna test system to detect shortcomings and weaknesses in the skill level of players

- Conducting training research using the proposed PETTLEP vital elements and using the Vienna test system in sports to confirm the effectiveness of this type of training.

- Use of Vienna test system, which is concerned with examination, measurement and diagnosis, when performing any psychological or cognitive measurement, because it gives correct and accurate results and help to diagnose all cases of weakness for players and practitioners through the information that appears in the form of data, tables and graphs specific to each player separately.

- The necessity of using modern technologies when performing any psychological tests, because they are characterized by accuracy and credibility and give real, accurate and concrete results instead of using traditional methods known in the past that do not give the same accuracy and reliability that modern technologies give.

- Holding training and education courses for workers in the sports field on how to use the Vienna test system to measure and evaluate the psychological, mental and skill capabilities of players. 


\section{First: Arabic References}

1 Briar, John Kaka Noman

2 Janan Nag Al-Jubouri

3 Magdy Hassan Yuosef

4 Magdy Hassan Yuosef

5 Mohamed Ibrahim Rakha

6 Mortada Kazem Abadi
(2017) : The bio equivalence of imagery and its effect on the transmission skill of young women in volleyball. Unpublished Master Thesis, Faculty of Physical Education for Boys, Alexandria University.

(2015) : Cognitive speed in terms of the Vienna test system and its relationship to the overwhelming shooting in volleyball; Faculty of physical education and sports science; University of Baghdad; Journal of Sports Science, volume eight, number: 27

(2017) : kinematic imagery in the sports field, Dar AlWafa- Dunia for Printing and Publishing, Egypt

(2016) : The functional bio equivalence of kinetic imagery in the sports field, Journal of Sports Science Applications, No. 90.

(2018) : The effect of the bio imagery program on improving the performance of the ball-pulling skill of a hockey young in terms of some kinematic variables. Unpublished Master Thesis, Faculty of Physical Education for Boys, Alexandria University.

(2019) : An analytical study in terms of Vienna tests for some psychological variables for players of different lines in football in Iraq; unpublished doctoral thesis: Alexandria University; Faculty of Physical Education for Girls.

\section{First: English References}

7 Biddle and Start

8 Cumming, J. and Williams, S.E.

9 Gill, D.L., and Williams, L
(1996) : Psychology of physical Education and Sports: A Practical Guide for Teachers", 3rd ed., F.I.T. Systems Ltd, U.K.

(2012) : The Role of imagery performance." The Oxford Handbook of Sport and Performance Psychology. Edited by Shane M. Murphy.

(2008) : Psychological Dynamics of Sport and Exercise (3rd ed.). Human Kinetics 
10 Gregg, M. J., and Clark, T.

11 Holmes, P. S., and Collins, D. J.

12 Johne M., Poliszczuk T., Poliszczuk D., and Dąbrowska Perzyna A.

13 Lang, P. J., Kozak, M. J., Miller, G. A., Levin, D. N., and McLean $\mathrm{Jr}, \mathrm{A}$.

14 Magill

15 Mańkowska M, Poliszczuk , Poliszczuk D, and Johne M.

16 Mastrangelo, P.M, Everton, W.J., and Jolton, J.A.

17 Nathanael Ong

18 Paul GerinDruckerei, and Wolkersdorf

19 Sanjiv Dutta and Dr.Agyajit Singh
(2007) : Theoretical and practical applications of mental imagery.

Proceedings of the International Symposium on Performance Science 2007 (pp. 295-300).

(2001) : The PETTLEP approach to motor imagery: a functional equivalence model for sport psychologists Journal of Applied Sport Psychology. 13(1): 60-83.

(2013) : Asymmetry of Complex Reaction Time in Female Epee Fencers of Different Sport Classes. J. Sport Tourism 30,25 - 34.

(1980) : Emotional Imagery: Conceptual Structure and Pattern of Somato - Visceral Response. Psychophysiology

(2004) : Motor learning: concepts and applications. 7th ed. Boston; United States: WCB/McGraw-Hill

(2015) : Visual perception and its effect on reaction time and time - movement anticipation in elite female basketball players. Pol J. Sport Tourism. 22, 3- 14 .

(2003) Deviant computer use at work: from bad to worse SMC'03 Conference Proceedings. 2003 IEEE International Conference on Systems, Man and Cybernetics. Conference Theme System Security and Assurance. VoI.3. 251263.

(2015) : The use of the Vienna Test System in sport psychology research: A review, International Review of Sport and Exercise Psychology https://www.researchgate.net/publication/2824 4813

(2014) Sport psychological ability: and personality assessment with the Vienna Test System SPORT 2.

(2013) : ABILITIES OF SCHOOL AND UNIVERSITY LEVEL ATHLETES INTERNATIONAL JOURNAL OF BEHAVIORAL SOCIAL AND MOVEMENTSCIENCES, Vol.02,No 
20 Schuhfried

21 Schuhfried, G.

(2013)

23 Smith, D., Wright, C., Allsopp, A., \& Westhead, $\mathrm{H}$

24 Syer, J., and Connolly, C.

25 Turosz MA, Sadowski J, Graczyk M., and Zróżnicowanie

(2010)
22 Smith, D., Hale, B., and Collins, D.

Training of Cognitive Abilities Catalogue .Modeling, Austria,87-101

Vienna Test System: Psychological assessment. moedlng, Austria: Schuhfried. www.schuhfried.com

(1998) : Imagery perspectives and karate performance (Perspective d'imageriementale et performance en karate). Journal of Sports Sciences. 16, 103-4.

(2007) It's All in the Mind: PETTLEP- Based Imagery and Sports Performance. Journal of Applied Sport Psychology. 19, 80-92

(1984) : Sporting body, sporting mind: an athlete's guide to mental training. . London; United Kingdom: Cambridge University Press

(2007) : interkorelacje zdolności koordynacyjnych ze zmiennymi psychicznymi w okresie przygotowawczym i startowym Kadry Polski wioślarzy [Individual differences and interactions of coordination abilities and mental variables in preparatory and starting periods of Polish national team rowers]. Medycyna Sportowa. 2007;3(6):149-154.

26 Riccardo, V., and Etzkowitz, H.

27 Weinberg, R. S.
(2008) : Does imagery work? Effects on performance and mental skills. Journal of Imagery Research in Sport and Physical Activity, 3(1)-20. 